\title{
A case of popliteal artery entrapment in an active duty soldier
}

\author{
Jacob Mathew
}

\begin{abstract}
Introduction: Popliteal Artery Entrapment Syndrome (PAES) is a less considered entity in active patients presenting with exertional lower extremity pain with associated claudication. Median time to diagnosis can be as high as 12 months and delay in surgical intervention can lead to increased morbidity. After treatment, recovery is promising with most patients returning to cardiovascular activity after three months. Case Report: We present the case of a 27-year-old active duty Caucasian male who initially presented for exertional right greater than left leg pain and was found on testing in the clinic to have absent distal extremity pulses with exercise. CT imaging revealed evidence of popliteal artery entrapment and surgical intervention was later pursued. We focus on the difficulty in diagnosing the condition given the plethora of other conditions that can present similarly. Furthermore, we discuss diagnostic modalities available along with management options available to the primary care physician. Conclusion: It is important to have a high index of suspicion for PAES in patients presenting with exertional claudication in the lower extremity and to understand what immediate testing can be done in the clinic and after evaluation, that can aid in diagnosis and management.
\end{abstract}

Jacob Mathew

Affiliation: Flight Surgeon, Department of Aviation Medicine, Evans Army Community Hospital, Fort Carson, CO, USA.

Corresponding Author: Jacob Mathew, Jr., DO, Department of Aviation Medicine, Bldg 1058; Fort Carson, CO 80913, USA; Email: jacob.mathew4.mil@mail.mil

Received: 12 February 2018

Accepted: 21 March 2018

Published: 07 May 2018
Keywords: Claudication, Leg pain, Lower extremity pain, Popliteal artery entrapment syndrome

\section{How to cite this article}

Mathew J. A case of popliteal artery entrapment in an active duty soldier. J Case Rep Images Med 2018;4:100046Zo9JM2018.

Article ID: 100046Zo9JM2018

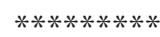

doi: 10.5348/100046Zo9JM2018CR

\section{INTRODUCTION}

Popliteal Artery Entrapment Syndrome (PAES) is a less commonly considered condition of either anatomic or functional etiology that can present with exertional pain to the lower extremity [1]. The differential diagnosis of lower extremity pain with exertion is quite broad which explains a median delay in diagnosis of patients with PAES of 12 months [2-3]. There are six types of entrapment syndromes comprised of five different anatomic causes, and one functional $[4,5]$. Diagnostic imaging includes ultrasound and angiography [6]. However, If diagnostic imaging is negative, but clinical suspicion remains, dynamic testing may aid in the diagnosis [6]. If surgical intervention is required, $90 \%$ of patients are able to resume aerobic activity three months, post-operatively [7]. Here, we present a patient with exertional pain with claudication to the lower extremity found to have politeal artery entrapment syndrome in a deployed setting.

\section{CASE REPORT}

A 27-year-old active duty Caucasian male initially presented to the Task Force aid station during a 


\section{EDORIUM Journals}

www.edoriumjournals.com/case-reports/jcrm

deployment to Afghanistan in support of Operation Freedom's Sentinel for exertional bilateral leg pain, right greater than left that had been ongoing from three months. He described a cramping sensation that occasionally became sharp starting at the knee and radiating down his leg that occurred only with running and performing calf raises and resolved after ten minutes of rest. When the episodes occurred, he stated his toes would feel cold. He denied pain solely at rest. He had no previous diagnoses of lower extremity issues, low back pain, and considered himself otherwise healthy.

His past medical history was notable for both inhalation (1/2 Packs Per Day) and chew tobacco chewing. He occasionally drank alcohol in social situations. He denied family history of cardiac disease.

He admitted to social alcohol but denied history of illicit drug use and had no failed drug tests in his military career. He had no known drug allergies.

Physical examination revealed a well-groomed male in no distress with a somewhat antalgic gait favoring his right leg. Cardiopulmonary exam was normal. Otherwise, $2+$ pulses were noted in the femoral, dorsalis pedis and posterior tibilalis arteries bilaterally. He had equal circumference of both calves, and only minor tenderness to palpation of the right calf itself but there was no overt discoloration or temperature difference upon palpation. After initial evaluation in our clinic, his symptoms were attributed to either muscle strain or stress fracture. Given the limited resources available, we were unable to obtain plain films. He was advised to temporarily cease his flight duties and was given a profile to restrict running for the next month. He was advised to return to our clinic in two months upon return from deployment for re-evaluation when we would have better access to diagnostic studies. We advised him that if he were to notice any development of neurovascular symptoms to include numbness, discoloration, palor, decreased temperature to palpation, fullness, or worsening pain he was to report back immediately at which point he would likely be transferred to a Role III hospital.

His symptoms remained stable and he was eventually followed up in our clinic back at Fort Carson, Colorado after our unit returned from deployment. Physical examination revealed persistent pain in his right calf. Circumferences were again equal, with no change to color or temperature in comparison to the left calf. The peripheral pulses of dorsalis pedis and posterior tibial artery were palpable at rest and were noted to cease (from $2+$ to 0 ) after 30 seconds of calf raises.

The complete blood count revealed a hemoglobin of $16.1 \mathrm{~g} / \mathrm{dL}$, hematocrit of $45.4 \%$, white blood cells of $7.4 \mathrm{~g} /$ $\mathrm{dL}$, and platelets of $200 \mathrm{x} 10(3) / \mathrm{mcL}$. The MCV was 85.9 fL. Coagulation studies and urinalysis were within normal limits. A lower extremity radiograph was performed to evaluate the patient's persistent pain, revealing no obvious evidence of fracture. Dynamic CT angiogram performed at our institution showed obliteration of the popliteal artery with plantar flexion of the left foot (Figures 1 and
2). No anatomic abnormalities were appreciated with the musculature. Based on the imaging, a diagnosis of functional popliteal artery entrapment was diagnosed. Doppler ultrasonography revealed no evidence of venous thrombosis.

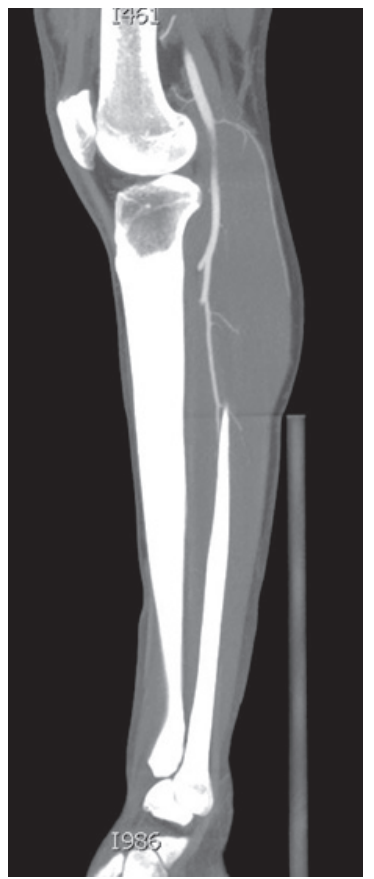

Figure 1: Sagittal CTA scans at the level of popliteal fossa after contraction of gastrocnemius muscle showing stenosis of the right popliteal artery.

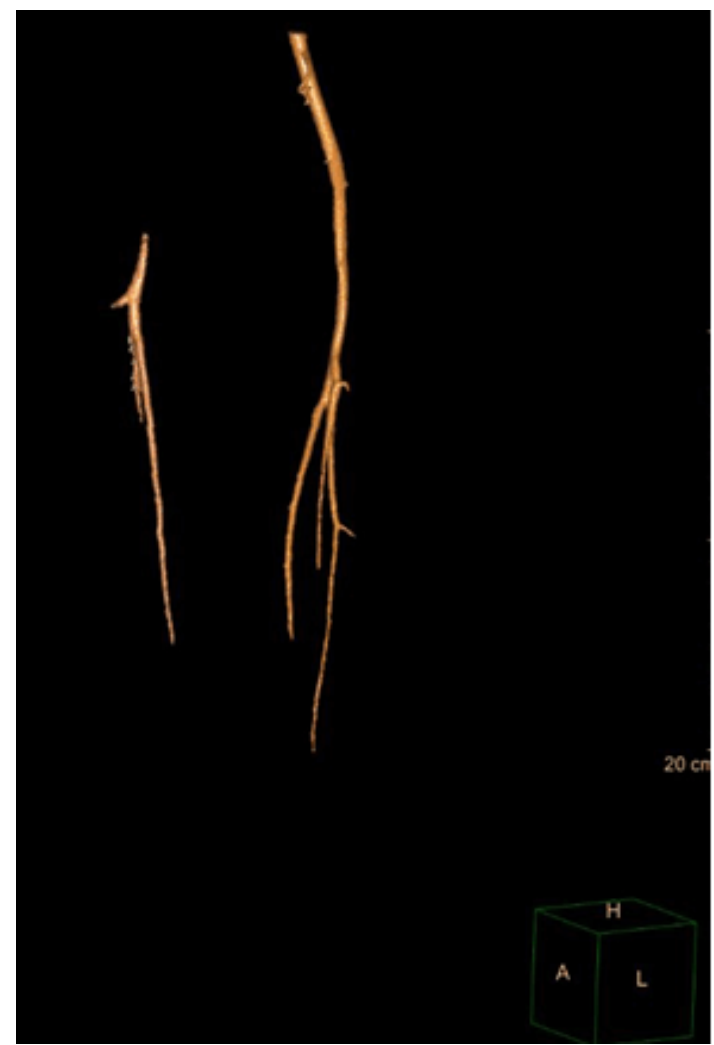

Figure 2: Three dimensional CTA of popliteal artery. Popliteal artery entrapment noted on right. 


\section{EDORIUM Journals}

The patient was admitted to another institution for surgical intervention. After evaluation by a vascular surgeon, right popliteal artery release was performed by making an incision in the posterior popliteal fossa at the mid-calf and extending medially in a curve pattern to the popliteal skin crease. The fascia was incised and the two planes of the gastrocnemius muscle were identified where the popliteal artery was then found and freed. Evaluation of the medial head of the gastrocnemius was resected off the lateral condyle to allow for the artery to move more freely.

His post-operative course was complicated by the development of deep venous thromboses to the posterior tibial and peroneal veins of the left leg which resolved after initiation of rivaroxaban.

After surgery, vascular claudication resolved rapidly however the patient continued to have pain secondary to the surgery itself and unfortunately was unable to return his soldier duties resulting in a medical discharge.

The patient continues to be followed by the Veterans Administration for care. He is ambulatory with a cane as needed. Pain has been well controlled without the need of over the counter or prescribed medications. He has gradually returned to exercising but has yet to start any sports activities.

\section{DISCUSSION}

The most common conditions considered in active individuals presenting with lower extremity limb pain often includes stress fractures, stress syndromes, muscle strains and compartment syndrome [2]. An often overlooked diagnosis that must be considered in particularly active individuals presenting with exertional lower extremity pain is Popliteal Artery Entrapment Syndrome, or PAES, as delay in diagnosis can lead to arterial occlusion, critical limb ischemia, post-stenotic dilitation, and aneurysm formation [3]. Reports suggest that the condition is diagnosed in only $1-3.5 \%$ of patients presenting with exertional extremity pain resulting in a median delay in diagnosis of 12 months $[2-3,8]$. The true prevalence of PAES, however is unknown as there is likely a large number of cases that go unreported or misdiagnosed. The syndrome has a male to female ratio of 15:1 with bilateral disease occurring in approximately 29 to $67 \%$ of cases [3].

PAES is considered a combination of both a vascular and musculoskeletal pathology that ultimately leads to significant claudication and neurologic symptoms in active individuals caused by popliteal artery compression by both the gastrocnemius and fascia of the soleus $[2,9]$. Surgical repair is often required to resolve mechanical compression or vascular damage [10].

The modified classification system Rich et al. [4] that was initially proposed by Love and Whelan involves six subtypes of PAES but is classically generalized into one of two types: anatomic and functional [5-6]. In anatomic PAES, often seen in sedentary males in the fifth decade of life, is due to anomalous anatomy of either the gastrocnemius, popliteal artery, or both [5]. Additionally, these anatomic differences are subclassified into five types based on the differing anatomy. Type 1 is an uncharacteristic medial arterial course around a normal medial head of gastrocnemius muscle. In Type 2, the abnormal medial head of the gastrocnemius inserts laterally on the distal femur and medially displaces the popliteal artery. In Type 3, the medial head of the gastrocnemius muscle wraps around the popliteal artery and entraps it, leading to compression. In Type 4, the popliteal artery is compressed by a band of the popliteus muscle. Type 5 is any form of the first four types that involves the popliteal vein. If the condition is not caused by an anatomic abnormality, then the patient is thought to have functional PAES, which is considered the sixth type. The functional type of the popliteal vessel compression was first described by Rignault and colleagues in 1985 where compression of the popliteal artery may be due to an anatomically normal but hypertrophic muscle [11]. In our case, the patient was classified as having functional PAES.

Clinical features in PAES include claudication to the anterior and posterior aspects of the leg with associated numbness and tingling in the foot often also seen $[5,12]$. Pain is often brought on by running uphill or repetitive jumping. In more advances cases, parasthesia may progress to pulselessness to both the posterior tibial and dorsalis pedis arteries.

To complicate the diagnosis, symptoms often co-exist in other conditions as well. For example, parasthesias to the sole of the foot while more often seen in PAES may also be seen with compartment syndrome [13]. A more specific finding is weak distal pulses when compared to the unaffected limb after calf raises (plantarflexion) [2]. Our patient presented with exertional pain to the lower extremity with complete loss of pulses with sustained activity.

The condition should be suspected in patients presenting with unexplained leg pain after or during exercise in which other more common diagnoses have been ruled out. Corneloup et al. report in their sample of 35 patients diagnosed with PAES a median age of 30.5 years. The relatively young active duty population that frequents the gym, such a condition should be held high in the differential diagnosis for all medical providers, especially those taking care of soldiers [13].

In our patient, there was a high index of suspicion of chronic exertional compartment syndrome (CECS) given his bilateral symptoms (albeit one extremity was worse than the other), gradual onset of pain with exercise, pain localized to a specific area of the leg (anterior tibia), and the reported sensation of the area feeling 'hard'. CECS has a reported incidence of $27-33 \%$ [1]. Patients will often report gradual onset of bilateral leg pain over a 20 minute period with exertion but no pain at rest [1]. Pain is reported to be isolated to a specific compartment of 


\section{EDORIUM Journals}

Table 1: Suggested but not all inclusive list of conditions to consider when patients present with suspected exertion induced lower extremity pain

\begin{tabular}{|c|c|c|c|c|}
\hline Condition & Signs/Symptoms & Distinguishing Features & Diagnosis & Treatment \\
\hline Stress Fracture & $\begin{array}{l}\text { Gradual onset } \\
\text { Localized } \\
\text { Worse with activity, } \\
\text { decreases with rest } \\
\text { With progression, pain } \\
\text { may be noted with } \\
\text { percussion at different } \\
\text { site }\end{array}$ & $\begin{array}{l}\text { Posteromedial Tibia rather } \\
\text { than anterior }\end{array}$ & $\begin{array}{l}\text { X-ray (repeat in } 2-3 \text { weeks } \\
\text { if suspicion high but imaging } \\
\text { negative) } \\
\text { Consider CT or MRI to } \\
\text { expedite diagnosis }\end{array}$ & $\begin{array}{l}\text { Conservative } \\
\text { treatment (rest for } \\
4-8 \text { weeks) } \\
\text { Ice } \\
\text { Failure of } \\
\text { conservative } \\
\text { treatment may } \\
\text { necessitate } \\
\text { surgery }\end{array}$ \\
\hline $\begin{array}{l}\text { Chronic Exertional } \\
\text { Compartment } \\
\text { Syndrome }\end{array}$ & $\begin{array}{l}\text { Leg pain and } \\
\text { tightness together; } \\
\text { may have numbness } \\
\text { in extremity; } \\
\text { normal exam with } \\
\text { rest, tenderness to } \\
\text { palpation noted after } \\
\text { exercise; may have } \\
\text { weak dorsiflexion and } \\
\text { plantarflexion }\end{array}$ & $\begin{array}{l}\text { May involve } 4 \\
\text { compartments (anterior, } \\
\text { lateral, deep, and posterior) } \\
\text { with anterior and lateral } \\
\text { the most common involved } \\
(95 \%)\end{array}$ & $\begin{array}{l}\text { Intracompartmental } \\
\text { Pressures (ICP); normal is } \\
5^{-15} \mathrm{mmHg} \text { at rest, and post } \\
\text { exercise is } 9-20 \mathrm{mmHg} \\
\text { MRI (most sensitive if done } \\
\text { post exercise) }\end{array}$ & $\begin{array}{l}\text { Modification of } \\
\text { activity } \\
\text { Fasciotomy }\end{array}$ \\
\hline $\begin{array}{l}\text { Popliteal Artery } \\
\text { Entrapment } \\
\text { Syndrome }\end{array}$ & $\begin{array}{l}\text { Claudication symptoms } \\
\text { in the anterior } \\
\text { and/or posterior } \\
\text { portions of the leg; } \\
\text { may be associated } \\
\text { with numbness in } \\
\text { foot in tibial nerve } \\
\text { distribution; pain } \\
\text { with uphill running or } \\
\text { jumping }\end{array}$ & $\begin{array}{l}\text { Six types with } 7^{\text {th }} \text { considered } \\
\text { functional }\end{array}$ & $\begin{array}{l}\text { Pulses decreased with passive } \\
\text { ankle dorsiflexion or active } \\
\text { ankle plantarflexion with the } \\
\text { knee extended } \\
\text { 1-minute post exercise ABI } \\
\text { may be decreased } \\
\text { Duplex US } \\
\text { Conventional angiography } \\
\text { CT angiography }\end{array}$ & Surgical \\
\hline Spinal Stenosis & $\begin{array}{l}\text { Pain often involves } \\
\text { thigh and lower } \\
\text { back; pain described } \\
\text { as aching, searing, } \\
\text { throbbing. Leg and } \\
\text { foot numbness is } \\
\text { often in a dermatomal } \\
\text { distribution. Reflexes } \\
\text { may be absent or } \\
\text { reduced }\end{array}$ & $\begin{array}{l}\text { Sciatica is caused by } \\
\text { compression of lower spinal } \\
\text { nerve }\end{array}$ & $\begin{array}{l}\text { Static and dynamic imaging } \\
\text { through X-ray } \\
\text { Electrodiagnostic studies may } \\
\text { be helpful }\end{array}$ & $\begin{array}{l}\text { Conservative } \\
\text { (rest; PT; } \\
\text { NSAIDs; Steroids) } \\
\text { to surgery }\end{array}$ \\
\hline
\end{tabular}

the leg, most commonly the anterior or deep posterior. In contrast to PAES, patients will report pain mostly in the superficial posterior portion of the leg. As with our patient, patients with CECS often have a sensation of 'hardness' with the pain. In our patient, while our initial suspicion pointed towards CECS, his mostly unilateral anterior tibial symptoms with no change in his routine exercise regimen pointed away from the diagnosis [14].

Muscle strain should also be considered. Literature suggests that the most common muscle involved is often the gastrocnemius [5]. While this was considered, with rest, his symptoms did not improve and with no evidence of palpable muscle tenderness, the diagnosis was effectively ruled out.
Stress fractures are common in the military population, with reports showing up to $5 \%$ of recruits inflicted [15]. Our patient did not have recent increase in exercise or activity levels and did not have palpable tenderness along the anterior portions of the tibia. Furthermore, rest which was initially employed did not lead to improvement in his symptoms. Similarly, medial tibial stress syndrome was considered but as previously stated, his lack of improvement with conservative measures and absent palpable tenderness along the posteromedial tibial shaft lowered our consideration for this being the culprit.

Finally, claudication was the last condition considered. Given his age and otherwise healthy status, the only risk factor he had for vascular claudication was 


\section{EDORIUM Journals}

his tobacco use. As a result, ankle-brachial indexes were not sought. Neurogenic claudication was unlikely in this patient with no history of acute or chronic back pain. In this case, physical examination and radiologic imagining studies showed clear evidence to point towards popliteal entrapment syndrome as the underlying cause for this soldier's symptoms.

When suspecting this condition, there are multiple diagnostic modalities available. In the clinic, specific provocative maneuvers can be employed. Knee extension with repetitive active ankle plantaflexion may reproduce diminished or overt loss of pulses to the above arteries [16]. An ankle-brachial index (ABI) may also be performed. While the resting 1-minute ABI is usually normal, a post exercise 1-minute ABI will often be diminished [4]. Imaging techniques include duplex ultrasound, conventional angiography, magnetic resonance angiography, and computed tomography angiography. Doppler ultrasound may display hemodynamic changes resulting from the contraction of gastrocnemius muscle [6]. Magnetic resonance imaging is for evaluation of the anatomy of the popliteal fossa. If vascular imaging is unremarkable but a high index of suspicion remains for PAES, the patient should perform plantar dorsiflexion until becoming symptomatic, and angiography should be repeated [17]. In our case, MRI arteriography was not available, therefore, CT arteriography was performed.

No randomized controlled trials have been performed to date regarding optimal treatment for patients with PAES. Often, if activity modification is not possible or does not result in resolution of symptoms, surgical intervention is required. Bypass is often endorsed over thromboendarterectomy with success rates reported to be between $70-100 \%$ for anatomy PAES, and 100\% for functional PAES [7].

The differential diagnosis for exercise induced lower extremity pain includes chronic exertional compartment syndrome, muscle strain, stress fracture, and claudication (Table 1) [8, 18, 19].

Following treatment, patients should continue longterm outpatient follow-up. The prognosis of surgicallycorrected PAES is often favorable if the diagnosis is made early. Following surgery, more than $90 \%$ of patients have a significant improvement in their symptoms and return to normal physical activity within three months [18].

With this case presentation, we aimed to emphasize the consideration of popliteal entrapment syndrome in the differential diagnosis in patients presenting with vascular claudication and chronic pain of the lower extremity. The aim of the surgical intervention is to restore the abnormal relationship between the artery and medial head of gastrocnemius and decompress the four compartments in leg. Long-term outcomes are promising with $90 \%$ of patients that undergo surgical intervention return to cardiovascular activity in 3 months [7].

\section{CONCLUSION}

Primary care physicians should consider a wide breadth of conditions when evaluating unilateral lower extremity pain. While popliteal entrapment syndrome is a very rare condition and may be missed on initial consideration, delay in treatment may increase morbidity in patients.

\section{REFERENCES}

1. Hislop M, Kennedy D, Cramp B, Dhupelia S. Functional popliteal artery entrapment syndrome: Poorly understood and frequently missed? A review of clinical features, appropriate investigations, and treatment options. J Sports Med (Hindawi Publ Corp) 2014;2014:105953.

2. Gaunder C, McKinney B, Rivera J. Popliteal artery entrapment or chronic exertional compartment syndrome? Case Rep Med 2017;2017:6981047.

3. Hameed M, Coupland A, Davies AH. Popliteal artery entrapment syndrome: An approach to diagnosis and management. Br J Sports Med 2018 Jan 19. pii: bjsports-2017-098704.

4. Bonasia DE, Rosso F, Cottino U, Rossi R. Exerciseinduced leg pain. Asia Pac J Sports Med Arthrosc Rehabil Technol 2015 May 2;2(3):73-84.

5. Rich NM, Collins GJ Jr, McDonald PT, Kozloff L, Clagett GP, Collins JT. Popliteal vascular entrapment. Its increasing interest. Arch Surg 1979 Dec;114(12):1377-84.

6. Love JW, Whelan TJ. Popliteal artery entrapment syndrome. Am J Surg 1965 May;109:620-4.

7. Erdoes LS, Devine JJ, Bernhard VM, Baker MR, Berman SS, Hunter GC. Popliteal vascular compression in a normal population. J Vasc Surg 1994 Dec;20(6):978-86.

8. Sinha S, Houghton J, Holt PJ, Thompson MM, Loftus IM, Hinchliffe RJ. Popliteal entrapment syndrome. J Vasc Surg 2012 Jan;55(1):252-62.e30.

9. Rich NM, Collins GJ Jr, McDonald PT, Kozloff L, Clagett GP, Collins JT. Popliteal vascular entrapment. Its increasing interest. Arch Surg 1979 Dec;114(12):1377-84.

10. Calanca L, Glauser F, Alatri A, Mazzolai L. Popliteal artery entrapment syndrome. [Article in French]. Rev Med Suisse 2013 Feb 6;9(372):311-4.

11. Gokkus K, Sagtas E, Bakalim T, Taskaya E, Aydin AT. Popliteal entrapment syndrome. A systematic review of the literature and case presentation. Muscles Ligaments Tendons J 2014 Jul 14;4(2):141-8.

12. Rignault DP, Pailler JL, Lunel F. The "functional" popliteal entrapment syndrome. Int Angiol 1985 JulSep;4(3):341-3.

13. Turnipseed WD. Functional popliteal artery entrapment syndrome: A poorly understood and often missed diagnosis that is frequently mistreated. J Vasc Surg 2009 May;49(5):1189-95.

14. Corneloup L, Labanère $\mathrm{C}$, Chevalier $\mathrm{L}$, et al. Presentation, diagnosis, and management of popliteal artery entrapment syndrome: 11 years of 


\section{EDORiUM Journals}

experience with 61 legs. Scand J Med Sci Sports 2018 Feb;28(2):517-23.

15. Fraipont MJ, Adamson GJ. Chronic exertional compartment syndrome. J Am Acad Orthop Surg 2003 Jul-Aug;11(4):268-76.

16. Bhatnagar A, Kumar M, Shivanna D, Bahubali A, Manjunath D. High incidence of stress fractures in military cadets during training: A point of concern. J Clin Diagn Res 2015 Aug;9(8):RCo1-3.

17. Rajasekaran S, Kvinlaug K, Finnoff JT. Exertional leg pain in the athlete. PM R 2012 Dec;4(12):985-1000.

18. Chun JY, Yella R, Gonzalez-Junyent C, et al. Popliteal artery entrapment syndrome - anatomy, imaging techniques and findings. European Society of Radiology 2012:1-15.

19. Araújo JD, Araújo Filho JD, Ciorlin E, et al. Entrapment of popliteal vessels: Diagnosis and treatment and the concept of functional entrapment. J Vasc Bras 2002;1(1):22-31.

$* * * * * * * * *$

\section{Acknowledgements}

Nathaniel Teague, MD

\section{Author Contributions}

Jacob Mathew - Substantial contributions to conception and design, Acquisition of data, Analysis and interpretation of data, Drafting the article, Revising it critically for important intellectual content, Final approval of the version to be published

\section{Guarantor of Submission}

The corresponding author is the guarantor of submission.

\section{Source of Support \\ None}

\section{Consent Statement}

Written informed consent was obtained from the patient for publication of this case report.

\section{Conflict of Interest}

Author declares no conflict of interest.

\section{Copyright}

(C) 2018 Jacob Mathew. This article is distributed under the terms of Creative Commons Attribution License which permits unrestricted use, distribution and reproduction in any medium provided the original author(s) and original publisher are properly credited. Please see the copyright policy on the journal website for more information.
Access full text article on other devices

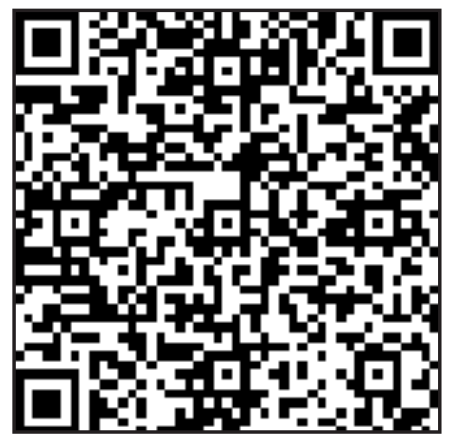

Access PDF of article on other devices

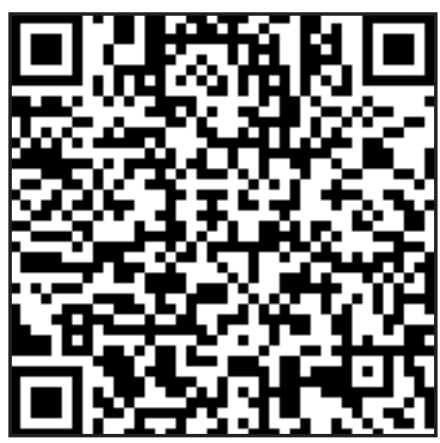




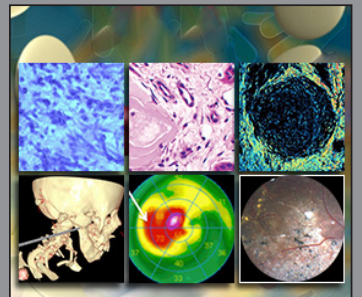

INTERNATIONAL JOURNAL OF CASE REPORTS AND IMAGES
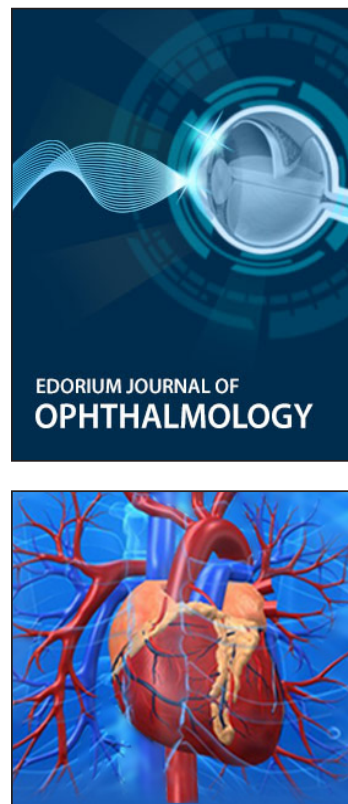

EDORIUM JOURNAL OF

CARDIOTHORACIC AND

VASCULAR SURGERY
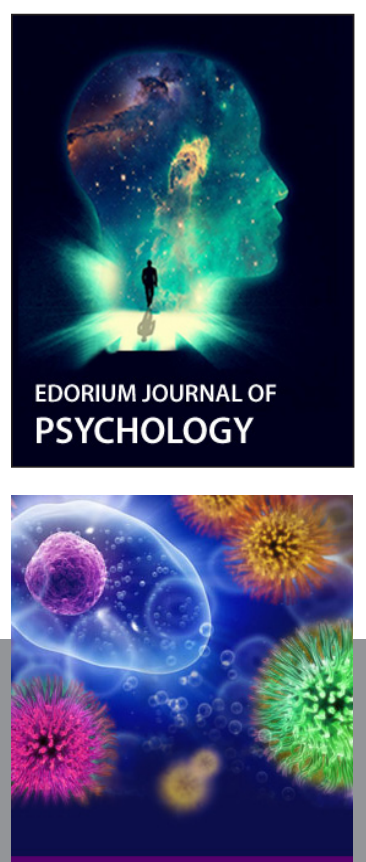

JOURNAL OF CASE REPORTS AND IMAGES IN INFECTIOUS DISEASES
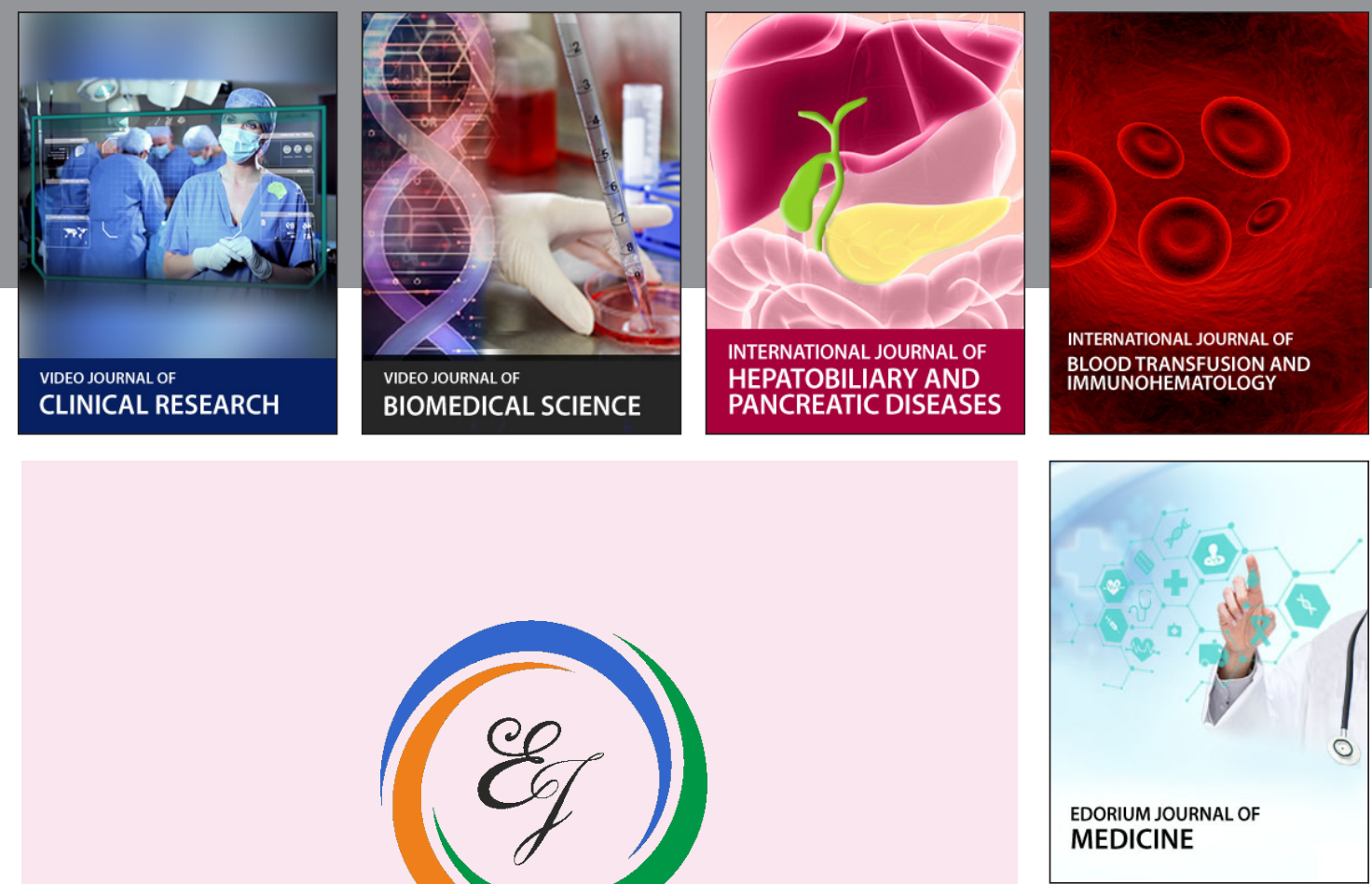

\section{Submit your manuscripts at}

www.edoriumjournals.com
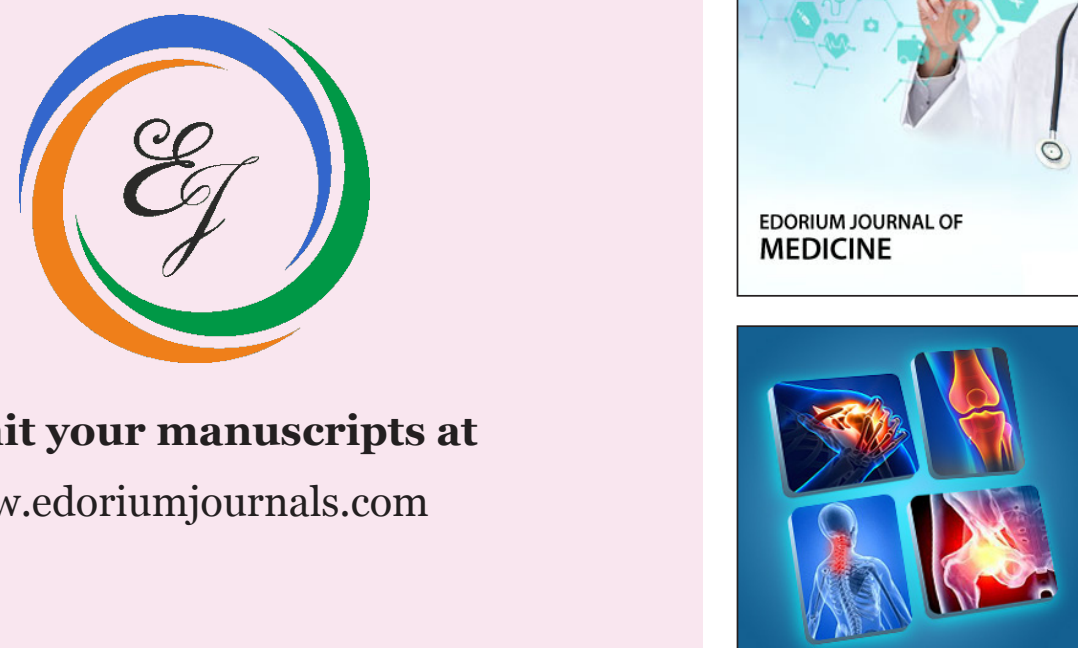

JOURNAL OF CASE REPORTS AND IMAGES IN ORTHOPEDICS AND RHEUMATOLOGY
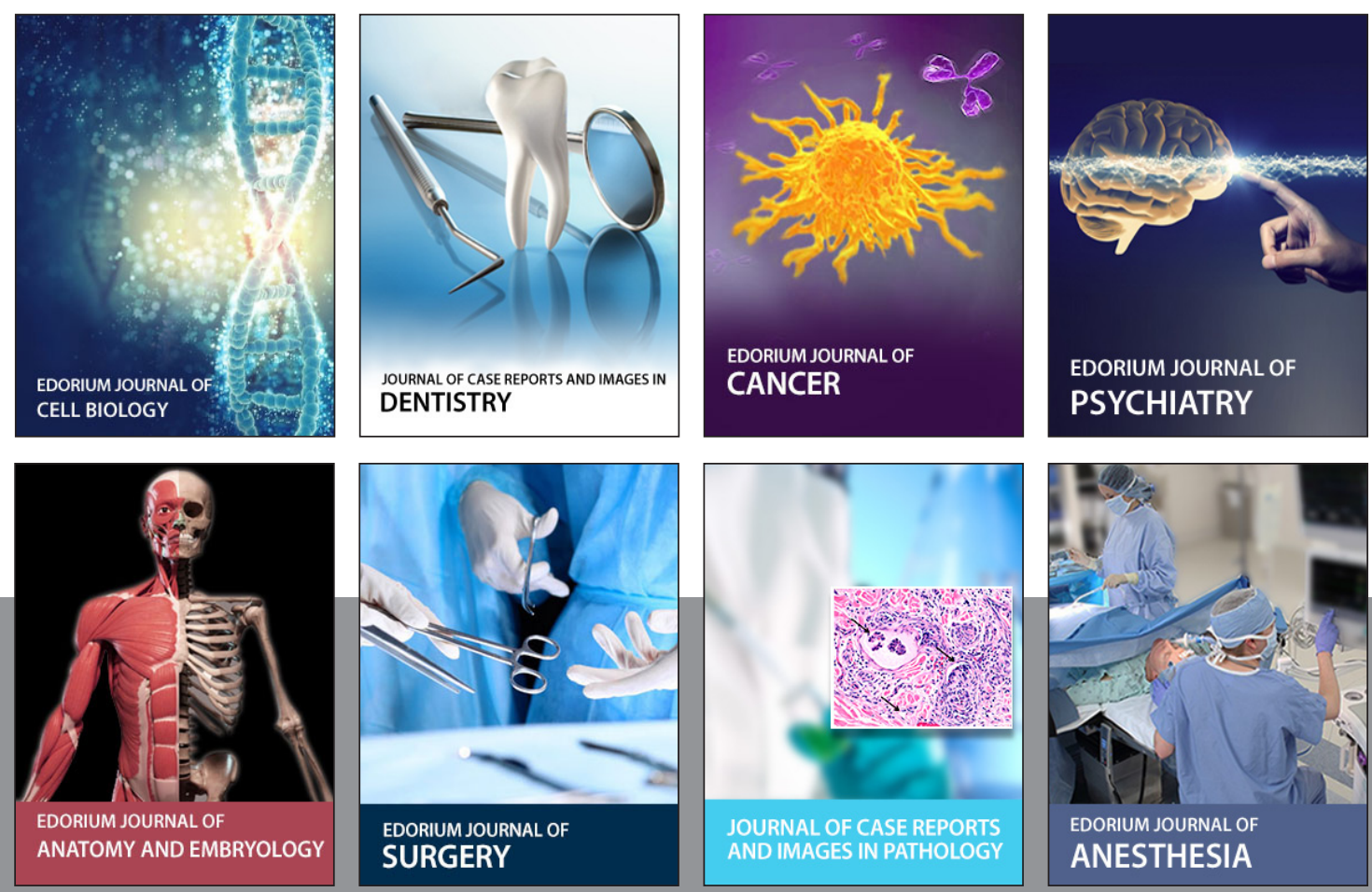